$\mathrm{pp}[73-84]$

\title{
Proposed methods for finding the basic acceptable solution for the transportation problems
}

\author{
Asmaa Salah Alddin Sulaiman* \\ asmaa.salah6500@gmail.com
}

\begin{abstract}
The data tend to be centered around a certain value that can be called a central value. In this case, the measures of central tendency are the function used to recognize this central value to represent the data. In some cases, the data are closing to the central value and sometimes more widespread. In order to measure the proximity or distance of data from that central value, measures of dispersion are used. In this research, some of these measures are used to find the basic acceptable solution for transportation problems. Better results are obtained by the researcher through using these measures by taking five applications with different capacities.
\end{abstract}

Keyword: Transportation problems, Northwest-corner method, Least-cost method, Vogel approximation method, Measures of central tendency, Measures of dispersion.

This is an open access article under the CC BY 4.0 license http://creativecommons.org/licenses/by/4.0/).

طرائق مقترحة لإيجاد الحل الأساسي المقبول لمشاكل النقل

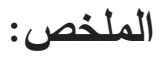

تميل البيانات إلى التمركز حول قيمة معينة يمكن تسميتها بالقيمة المركزية. في هذه الحالة ،

وتكون مقاييس النزعة المركزية هي الدالة المستخدمة للتعرف على هذه القيمة المركزية لتمثيل

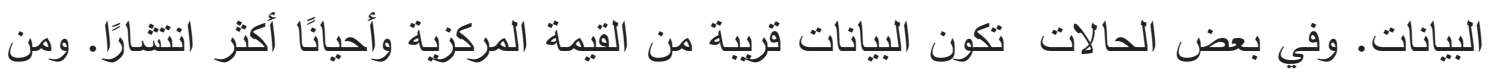

أجل قياس القرب أو البعد بين البيانات من تلأك القيمة المركزية ، نم استخدام مقاييس التشتئ.

تم في هذا البحث ، استخدام بعض هذه المقاييس لإيجاد الحل الأساسي المقبول لمشاكل النقل.

وحصل الباحث على نتائج أفضل باستخدام هذه المقاييس بأخذ خمسة تطبيقات بسعات مختلفة.

* Assistant Lecturer / Department of Mathematics / College of Basic Education / University of Telafer. 


\section{Introduction}

The main problem "managers directed is how to allocate limited resources among various activities or projects. Linear programming ( LP), is a method of allocating sources ideally. One of the most widely used operation research tools was decision making that helps can in almost every manufacturing industry, in financial and service organizations. In linear expression programming, programming refers to mathematical programming. In this context, it refers to a process planning that allocates resources - work, materials, machinery, capital - probably the best way to reduce cost or to increase profits". In LP, these sources are known as resolution variables. Standard for selecting the best values of decision variables (e.g., to increase profits or reduce costs), known as the objective function. Restrictions in the form of source availability are known as constraints. The linear word refers to that standard to select the best values of decision variables which can be by describing a linear function of these variables; this is a mathematical function that includes only the first powers of variables without cross-products.

Transport problems are one of the most important and successful applications of quantification analysis of business problems that was solved in the physical distribution of products.

"As their purpose is to reduce the cost of shipping goods from one location to another so that the needs of each arrival area is met and all shipping location works within their capacity. However, quantitative analysis has been used for many problems other than the physical distribution of goods. for example, it was used to place employees efficiently in some jobs within the organization". (this application is sometimes called assignment problem)[Reeb and Leavengood,2002]. It is said that the transportation problem is balanced if the quantification of all sources equals quantitative demand in all places and the so-called imbalance in other cases[Taghrid,2009]. "The structure of the transport problem allows us to solve it with a faster, more economical algorithm than simplex. Problems of this kind contain thousands of variables and constraints and can be solved in a few seconds on the computer. In fact, we can solve a relatively large transportation problem by hand. There are some requirements to place an LP problem in Transport problem class" [Reeb and Leavengood,2002].

The basic "transport problem was originally developed by Hitchcock Transport problems can be designed as standard linear programming problem. The problem can be solved by the Simplex method. Several heuristic techniques are available to obtain a basic initial solution, although 
some heuristics can find a preliminary solution very quickly, and often the solution you find is not very good in terms of total cost and small size. On the other hand, some heuristics may not find a first solution quickly, but the solution you find is often very good in terms of reducing total cost. There are specialized algorithms for the transport problem which are more efficient than the simple algorithm". The best known heuristics methods are the North west corner, Best cell method and the Vogel approximate method [Samuel and Venkatachalapathy,2013].

\section{Related Works}

In 2002, AL-Sabawi and Hayawi presented a new proposal to solve the transport model using a new method different from the previous known methods by taking the differences between the largest cost and the lowest cost of the transport model. They compared their method with Vogel approximate.

The research presented by Reeb and Leavengoode in 2002 put the problem of moving in the form of ordinary linear programming and then solved it using the computer using Lindo program. This program solves the problem of transport faster than the manual solution using the Simplex method, especially if the transport problem is large. The research also included clarifying the phenomenon of 'degeneracy' which occurs when the number of squares occupied is not equal to the number of rows + the number of columns -1 (Sources + Destinations -1 ). The researchers also explained that the methods of solving transport problems such as the NorthWest corner method and the approximate Vogel method can be used to solve problems other than the transport problem such as the assignment problem. In 2007, AL-Badri and Saleh reviewed the proposed new method, which is the average method for improving, developing and evaluating the acceptable basic solution compared with the Vogel method. The first basic solution to the transport problem obtained from the proposed methods gave less cost compared with the approximate Vogel method. Thus, indicating the efficiency and possibility of this method to realize the basic solution and therefore the best solution will not be difficult and complex.

Abdul Quddoos et al. in 2012 proposed a new method to solve the problem of transport. The ASM method, to find the best solution for a wide range of transport problems. This method is easy to understand and apply even by the layman. It is also a profitable way for decision makers who deal with restricted problems, This method gives the ideal solution as soon as possible. Moreover, a proposed Samuel and Venkatachalapathy method in 2013, to improve Zero Point method for finding an optimal solution using function principle in which transportation costs are represented as triangular fuzzy number. The methodology of "Improved Zero Point 
Method (IZPM) is a simple and efficient method that is better than the existing methods, easy to understand and can also give an optimal solution".

\section{Transportation problems}

The transportation problem is a special case of linear programming problems. It is easy to formulate the linear programming model in its initial and binary form after it is arranged in a format matrix, and it follows that:

$\mathrm{m}$ : Represents the number of sources which is $\mathrm{S}_{1}, \mathrm{~S}_{2}, \ldots, \mathrm{S}_{\mathrm{m}}$ with capacity supply and it is $a_{1}, a_{2}, \ldots, a_{m}$.

$\mathrm{n}$ : Represents the number of destinations which is $\mathrm{D}_{1}, \mathrm{D}_{2}, \ldots, \mathrm{D}_{\mathrm{n}}$ with a capacity demand and it is $b_{1}, b_{2}, \ldots, b_{n}$.

$\mathrm{C}_{\mathrm{ij}}$ : Represents the cost of moving one unit from the source (i) to destination (j) .

$\mathrm{X}_{\mathrm{ij}}$ : Represents the quantity or number of units to be transferred from the source (i) to destination ( $\mathrm{j}$ ), and that the linear programming model in its initial form of transport problem is as follows:

minimize $z=\sum_{j=1}^{n} \sum_{i=1}^{m} C_{i j} X_{i j}$

s.t.

$\sum_{j=1}^{n} X_{i j}=a_{i} \quad ; i=1,2, \ldots, m$

$\sum_{i=1}^{m} X_{i j}=b_{j} \quad ; j=1,2, \ldots, n$

$X_{i j} \geq 0$

Before the start of an acceptable basic solution and in any way the model should have been balanced by equal or equivalent to the total required quantities with the total quantities offered, and mathematically expressed

$\sum_{i=1}^{m} a_{i}=\sum_{j=1}^{n} b_{j}$

When the quantities required are greater than the quantities offered this means that

$\sum_{i=1}^{m} a_{i}<\sum_{j=1}^{n} b_{j}$

Add to the decision-making matrix (transport matrix) Dummy Source, it works on processing the quantity in which the deficit amount is as follows: 
$S_{m+1}=\sum_{j=1}^{n} b_{j}-\sum_{i=1}^{m} a_{i}$

Note that the cost of the Dummy source is zero $C_{m+1, j}=0$ and when the quantities required are smaller than the quantities offered this means that

$\sum_{i=1}^{m} a_{i}>\sum_{j=1}^{n} b_{j}$

Add to the decision-making matrix (transport matrix) Dummy Destination, It works on processing the quantity in which the deficit amount is as follows:

$D_{n+1}=\sum_{i=1}^{m} a_{i}-\sum_{j=1}^{n} b_{j}$

Note that the cost of the Dummy Destination is zero $C_{i, n+1}=0$ and to find the basic solution acceptable to the transport model. There are several different methods in terms of time and effort required to reach the initial solution. Three most commonly used methods to obtain an acceptable basic solution are:

1) Northwest-corner method:

This is one of the easiest ways to go, since you do not take into account costs using any scientific logic in the distribution process (distribution of available quantities)

\section{2) Least-cost method:}

This is a better way than the previous one, considering the cost of transportation from the source to the center

3) Vogel's approximation method [Hamdy,2011] [Taghrid,2009].

\section{Proposed Methods}

The methods proposed by the researcher are simple to implement and can also be the basic solution to the problem of balance Transportation:

1) Harmonic mean method: The following are the basic steps for this method:

a) Calculate the harmonic mean of the costs in each row and column according to the following equation:

$$
\bar{H}=\frac{n}{\sum_{i=1}^{n} \frac{1}{c_{i}}}
$$


b) Determine the highest harmonic mean in all rows and columns and then choose the cell containing the least cost to give the appropriate amount of available (supply) to meet the needs (demand).

c) Delete the row that ran out of the supply or column that was filled in the demand so as not to enter into the harmonic mean again.

d) Repeat steps (a-c), then calculate the total cost.

\section{2) Quadratic mean method:}

a) Calculate the Quadratic mean of the costs in each row and column according to the following equation:

$$
\bar{Q}=\sqrt{\frac{\sum_{i=1}^{n} c_{i}{ }^{2}}{n}}
$$

b) Determine the highest Quadratic mean in all rows and columns and then choose the cell containing the least cost to give the appropriate amount of available (supply) to meet the needs (demand).

c) Delete the row that ran out of the supply or column that was filled in the demand so as not to enter into the Quadratic mean again.

d) Repeat steps (a-c), then calculate the total cost.

\section{3) Median method:}

a) Calculation of the median of the costs in each row and column by ascending order ( or descending),

If the number of costs is even, the median represents the arithmetic mean of the two values in order $\frac{n}{2}$ and $\frac{n}{2}+1$, but if the number of costs is odd, the median represents the value of order $\frac{n+1}{2}$.

b) Determine the highest median in all rows and columns and then choose the cell containing the least cost to give the appropriate amount of available (supply) to meet the needs (demand).

c) Delete the row that ran out of the supply or column that was filled in the demand so as not to enter into the median again.

d) Repeat steps (a-c), then calculate the total cost.

4) Mean deviation method:

a) Calculate the Mean deviation of the costs in each row and column according to the following equation: 
M.D. $=\frac{\sum_{i=1}^{n}\left|c_{i}-\bar{c}\right|}{n}$

b) Determine the highest Mean deviation in all rows and columns, and then choose the cell containing the least cost to give the appropriate amount of available (supply) to meet the needs (demand).

c) Delete the row that ran out of the supply or column that was filled in the demand so as not to enter into the Mean deviation again.

d) Repeat steps (a-c), then calculate the total cost.

\section{5) Coefficient of variation method:}

a) Calculate the Coefficient of variation of the costs in each row and column according to the following equation:

C.V. $=\frac{S}{\bar{c}} \times 100$

b) Determine the highest Coefficient of variation in all rows and columns, and then choose the cell containing the least cost to give the appropriate amount of available (supply) to meet the needs (demand).

c) Delete the row that ran out of the supply or column that was filled in the demand so as not to enter into the Coefficient of variation again.

d) Repeat steps (a-c), then calculate the total cost.

6) Mid-Range method:

a) Calculate the Mid-Range of the costs in each row and column according to the following equation:

M.R. $=\frac{c_{\min }+c_{\max }}{2}$

b) Determine the highest Mid-Range in all rows and columns, and then choose the cell containing the least cost to give the appropriate amount of available (supply) to meet the needs (demand).

c) Delete the row that ran out of the supply or column that was filled in the demand so as not to enter into the Mid-Range again.

d) Repeat steps (a-c), then calculate the total cost. 


\section{Numerical results}

In order to observe the best methods proposed in this research, five examples of different transport models are presented. The total cost of the proposed methods are calculated and compared with the classical methods as follows:

Example 1 [AL-Sabawi and Hayawi,2002]:

\begin{tabular}{|c|c|c|c|}
\hline & $D_{1}$ & $D_{2}$ & Supply \\
\hline$S_{1}$ & 4 & 2 & 60 \\
\hline$S_{2}$ & 7 & 5 & 40 \\
\hline$S_{3}$ & 3 & 10 & 70 \\
\hline Demand & 105 & 65 & 170 \\
\hline
\end{tabular}

Table 1: Results for Example 1

\begin{tabular}{|l|c|}
\hline Methods & Total Cost \\
\hline Northwest-corner & 1185 \\
\hline Least-cost & 600 \\
\hline Vogel approximation & 600 \\
\hline Harmonic mean & 600 \\
\hline Quadratic mean & 600 \\
\hline Median & 600 \\
\hline Mean deviation & 600 \\
\hline Coefficient of variation & 600 \\
\hline Mid-Range & 600 \\
\hline
\end{tabular}

Example 2 [Sabir,2009]:

\begin{tabular}{|c|c|c|c|c|c|}
\hline & $D_{1}$ & $D_{2}$ & $D_{3}$ & $D_{4}$ & Supply \\
\hline$S_{1}$ & 7 & 3 & 8 & 2 & \\
\hline$S_{2}$ & 5 & 6 & 11 & 12 & 300 \\
\hline$S_{3}$ & 10 & 4 & 7 & 6 & 300 \\
\hline Demand & 80 & 170 & 190 & 160 & 600 \\
\hline
\end{tabular}


Table 2: Results for Example 2

\begin{tabular}{|l|c|}
\hline Methods & Total Cost \\
\hline Northwest-corner & 4010 \\
\hline Least-cost & 3450 \\
\hline Vogel approximation & 3210 \\
\hline Harmonic mean & 3210 \\
\hline Quadratic mean & 3360 \\
\hline Median & 3210 \\
\hline Mean deviation & 3210 \\
\hline Coefficient of variation & 3210 \\
\hline Mid-Range & 3210 \\
\hline
\end{tabular}

Example 3 [AL-Badri and Saleh,2007] :

\begin{tabular}{|c|c|c|c|c|c|}
\hline & $D_{1}$ & $D_{2}$ & $D$ & $D_{4}$ & Supply \\
\hline$S_{1}$ & 20 & 16 & 14 & 20 & \\
\hline \multirow[b]{2}{*}{$S_{2}$} & 0 & 15 & & 10 & \\
\hline & 7 & & 10 & 10 & 8 \\
\hline \multirow{2}{*}{$S_{3}$} & 8 & 13 & 5 & 9 & \\
\hline & & & & & 7 \\
\hline$S_{4}$ & 9 & 6 & 5 & 11 & \\
\hline Demand & 5 & 10 & 5 & 9 & 29 \\
\hline
\end{tabular}

Table 3: Results for Example 3

\begin{tabular}{|l|c|}
\hline Methods & Total Cost \\
\hline Northwest-corner & 392 \\
\hline Least-cost & 308 \\
\hline Vogel approximation & 308 \\
\hline Harmonic mean & 306 \\
\hline Quadratic mean & 306 \\
\hline Median & 306 \\
\hline Mean deviation & 308 \\
\hline Coefficient of variation & 308 \\
\hline Mid-Range & 306 \\
\hline
\end{tabular}


Example 4 [AL-Sabawi and Hayawi,2002]:

\begin{tabular}{|c|c|c|c|c|c|c|}
\hline & $D_{1}$ & $D_{2}$ & $D_{3}$ & $D_{4}$ & $D_{5}$ & Supply \\
\hline$S_{1}$ & 4 & 3 & 1 & 2 & 6 & 65 \\
\hline$S_{2}$ & 5 & 2 & 3 & 4 & 5 & 50 \\
\hline$S_{3}$ & 3 & 5 & 6 & 3 & 2 & 40 \\
\hline$S_{4}$ & 2 & 4 & 4 & 5 & 3 & 20 \\
\hline$S_{5}$ & 4 & 3 & 6 & 5 & 1 & 25 \\
\hline Demand & 60 & 60 & 30 & 40 & 10 & 200 \\
\hline
\end{tabular}

Table 4: Results for Example 4

\begin{tabular}{|l|c|}
\hline Methods & Total Cost \\
\hline Northwest-corner & 760 \\
\hline Least-cost & 420 \\
\hline Vogel approximation & 420 \\
\hline Harmonic mean & 505 \\
\hline Quadratic mean & 420 \\
\hline Median & 420 \\
\hline Mean deviation & 420 \\
\hline Coefficient of variation & 420 \\
\hline Mid-Range & 475 \\
\hline
\end{tabular}

Example 5 [AL-Badri and Saleh,2007]:

\begin{tabular}{|c|c|c|c|c|c|c|c|}
\hline & $D_{1}$ & $D_{2}$ & $D_{3}$ & $D_{4}$ & $D_{5}$ & $D_{6}$ & Supply \\
\hline$S_{1}$ & 5 & 1 & 2 & 3 & 4 & 7 & 400 \\
\hline \multirow{2}{*}{$S_{2}$} & 7 & 2 & 3 & 1 & 5 & 6 & \multirow[b]{2}{*}{500} \\
\hline & & & & & & & \\
\hline \multirow{2}{*}{$S_{3}$} & 9 & 1 & 9 & 5 & 2 & 3 & \multirow[b]{2}{*}{300} \\
\hline & & & & & & & \\
\hline$S_{4}$ & 6 & 5 & 8 & 4 & 1 & 4 & 150 \\
\hline \multirow{2}{*}{$S_{5}$} & 8 & 7 & 11 & 6 & 4 & 5 & \multirow[b]{2}{*}{600} \\
\hline & & & & & & & \\
\hline$S_{6}$ & 2 & 5 & 7 & 5 & 2 & 1 & \multirow{2}{*}{$\begin{array}{c}350 \\
2300\end{array}$} \\
\hline Demand & 300 & 500 & 700 & 300 & 250 & 250 & \\
\hline
\end{tabular}


Table 5: Results for Example 5

\begin{tabular}{|l|c|}
\hline Methods & Total Cost \\
\hline Northwest-corner & 11100 \\
\hline Least-cost & 9100 \\
\hline Vogel approximation & 7100 \\
\hline Harmonic mean & 6650 \\
\hline Quadratic mean & 6650 \\
\hline Median & 6650 \\
\hline Mean deviation & 6400 \\
\hline Coefficient of variation & 7100 \\
\hline Mid-Range & 6650 \\
\hline
\end{tabular}

Table 6: shows the total cost values for the five Examples used in the research

\begin{tabular}{|c|c|c|c|c|c|c|c|c|c|c|}
\hline Application & \begin{tabular}{|c|} 
Methods of \\
solution \\
$\begin{array}{c}\text { Application } \\
\text { Capacity }\end{array}$ \\
\end{tabular} & $\begin{array}{c}\text { North } \\
\text { west } \\
\text { corner }\end{array}$ & $\begin{array}{l}\text { Least } \\
\text { cost }\end{array}$ & Vogel & $\begin{array}{c}\text { Harmonic } \\
\text { mean }\end{array}$ & $\begin{array}{l}\text { Quadratic } \\
\text { mean }\end{array}$ & Median & $\begin{array}{c}\text { Mean } \\
\text { deviation }\end{array}$ & $\begin{array}{c}\text { Coefficient } \\
\text { of variation }\end{array}$ & $\begin{array}{c}\text { Mid } \\
\text { Range }\end{array}$ \\
\hline 1 & $(3 \times 2)$ & 1185 & 600 & 600 & 600 & 600 & 600 & 600 & 600 & 600 \\
\hline 2 & $(3 \times 4)$ & 4010 & 3450 & 3210 & 3210 & 3360 & 3210 & 3210 & 3210 & 3210 \\
\hline 3 & $(4 \times 4)$ & 392 & 308 & 308 & 306 & 306 & 306 & 308 & 308 & 306 \\
\hline 4 & $(5 \times 5)$ & 760 & 420 & 420 & 505 & 420 & 420 & 420 & 420 & 475 \\
\hline 5 & $(6 \times 6)$ & 11100 & 9100 & 7100 & 6650 & 6650 & 6650 & 6400 & 7100 & 6650 \\
\hline
\end{tabular}

In the above table, when the six proposed methods and the three classic methods are used, the results turned out to be as follows:

1) Results of the first example are similar to Least-cost and Vogel methods due to the nature of the available data of this example. Namely, it is the best improvement of solution (i.e. least possible cost) because it has not given worse results than North West-corner method.

2) Results of the second example are better than North West-corner and Least-cost methods. However, they are equal to Vogel method. This is due to the same reason of the first example. Yet, different results are obtained using Quadratice mean. Still, it is better than North West-corner and Least-cost methods despite, the fact that it is higher in results than Vogel method.

3) Results of the third example are better than the three classic methods except Coefficient of variation and Mean deviation methods. But, it is better than North West-corner method and not worse than Vogel and Least-cost methods.

4) For the same reason, results of the fourth example are better than North West-corner method except Harmonic mean and Mid-Range methods. 
5) Results of the fifth example are better than the three classic methods except Coefficient of variation method which has given the same as Vogel's .It is better than North West-corner and Least-Cost methods; still not worse than Vogel's.

\section{Conclusion}

Statistical measures have been seen from observing and discussing Table (6). These are either Central Tendency or Scattering Measures. They can be used as methods to find the basic acceptable solution for transportation problems. These methods have been proposed in the research. Although the results are variant, they are not worse than the three classic methods. The reason goes back to the nature of data used in the research. In addition, it was concluded that the proposed methods are easy to apply to all types of transport problems and are an important decisionmaking tool in order to reach the basic solution of the lowest possible total cost of goods transportation. The mathematical steps of these methods are easy to implement in real applications.

\section{References}

1) Quddoos,A., S. Javaid and M.M.Khalid, 2012, A New Method for Finding an Optimal Solution for Transportation Problems, International Journal on Computer Science and Engineering (IJCSE), Vol. 4, No. 07,pp 1271-1274 .

2) Al-Badri, F., F.and Saleh, S., A., 2007, A Proposed Method for Finding the Basic (acceptable) Solution to the Transportation Problem, Journal of Economic and Administrative Sciences, Vol. 13, No. 48,pp 300-313 .

3) Al-Sabawi, A., M. and Hayawi, H., A., 2002, A Proposed Method to solve Transportation Model, Iraqi Journal of Statistical Sciences, No. 4, pp 61-71.

4) Hamdy,A.,T., 2011, Operation Research An Introduction , Pearson Education, Inc., Prentice hall, 9 edition, Newjersey,USA.

5) Reeb, J. And Leavengood, S., 2002, Transportation Problem: A Special Case for Linear Prpgramming Problems, Published June (C) 2002 Oregon State University.

6) Sabir, J., A., 2009, Operations Research in Accounting , Cairo University, Egypt.

7) Samuel, A., E.and Venkatachalapathy, M., 2013, IZPM for Unbalance Fuzzy Transportation Problems , International Journal of Pure and Applied Mathmatics, Vol. 86, No. 4, pp 689-700 .

8) Taghrid, I., 2009, Solving Transportion Problem Using Object-Oriented model , International Journal on Computer Science and Network Security (IJCSNS),Vol. 9.NO. 2,pp 353-361 . 